\title{
Closing the (protective services) gap: why size does matter when determining optimal Level 2 service delivery
}

\author{
Michael Townsley ${ }^{\dagger}$ and John W Bond ${ }^{\ddagger}$ \\ †(Corresponding author) Jill Dando Institute of Crime Science, University College London, \\ Second Floor Brook House, 2-16 Torrington Place, London, WC1E 7HN. \\ Tel: +44 (0)20 7679 0820; Fax: +44 (0)20 7679 0828; email: m.townsley@ucl.ac.uk \\ $\ddagger$ Scientific Support Unit, Northamptonshire Police, Wootton Hall, Northampton, NN4 OJQ. \\ Email: john.bond@northants.pnn.police.uk
}

Received 11 April 2006; revised and accepted 29 August 2006

Keywords: detection, forensic, amalgamation

\begin{abstract}
Michael Townsley is a Senior Research Fellow at the Jill Dando Institute. He completed an Applied Mathematics and Statistics degree before embarking on a $P h D$ in Criminology. Having studied the spatial and temporal distributions of burglary, and taken time out to work on a number of crime prevention projects, he left Australia to work in Liverpool, England. Time spent advising Merseyside Police on crime analysis was put to good use when he was employed as a manager of a New Deal for Communities (NDC) crime theme. Current interests focus on problem oriented policing, prolific offenders and crime analysis. His current projects involve the incorporation of forensic data with routine crime analysis.
\end{abstract}

John W. Bond is Head of Forensic Science for Northamptonshire Police. His research interests centre on the use of forensic science to enhance the detection of crime, principally through the analysis of forensic data and the development of new techniques for the enhancement of fingerprints. He has research affiliations with a number of UK universities and lectures on forensic science at Sussex University.

\begin{abstract}
The September 2005 review of policing structure in England and Wales by Her Majesty's Inspectorate of Constabulary (HMIC) is considered in terms of its impact on forces' ability to detect volume crime (crime types that occur in relatively large numbers). We demonstrate that there is no relationship between force size and detection rates, however there is a difference with respect to the means of detecting volume crime. Smaller forces tend to record a greater proportion of their volume crime detections through forensic means. We explore one possibility of this observation greater forensic deployment due to lower demand or better management - and find some evidence to support better management of forensic resources in smaller forces.
\end{abstract}

\section{INTRODUCTION}

In England and Wales mainstream policing is oriented around a hierarchy of criminality, labelled Levels 1, 2 and 3. Level 1 is concerned with local issues and is considered appropriately dealt with at the Basic Command Unit (BCU) level. Level 3 focuses on serious and organised crime operating at a national or international level and is the remit of the Serious Organised
International Journal of Police Science and Management, Vol. 9 No. 2, 2007, pp. 183-192. (C) Vathek Publishing, $1461-3557$ 
Crime Agency (SOCA), the amalgamation of the National Crime Squad, National Criminal Intelligence Service, Home Office departments responsible for organised immigration crime and Customs staff experienced in serious drug trafficking and criminal asset confiscation. Level 2 deals with 'cross-border' crime - essentially criminal acts perpetrated between two police jurisdictions.

The current regime of police service delivery is oriented around Level 1 criminality, with Level 3 the subject of a dedicated (albeit newly formed) agency. Level 2 criminality is often the subject of spare capacity, regional teams drawn together on an ad hoc basis or some other non-systemic approach. Apropos of this, O'Connor (2005, p. 24) quotes from Stephenson $(2004$, p. 13) that fewer than 6 per cent of the estimated 1,500 organised (Level 2) criminal networks active nationally, were targeted by police in any given year.

It was in the light of apparent lack of capacity at tackling Level 2 criminality that a ministerial report, Mind the (Level 2) Gap, recommended (among other things) that '[a] confidential national assessment of protective services should be carried out by HMIC' (O'Connor, 2005, p. 88). The fulfilment of that recommendation was the recently published, Closing the Gap, HMIC review, authored by Denis O'Connor. Commissioned by the Home Secretary and published in September 2005, the report is a review of the organisational structure of policing in England and Wales and considers the ability of the existing structure of policing to deal effectively with protective services as well as volume crime (the focus of the current structure). A secondary objective was to determine whether collaboration was an appropriate method to address service delivery shortfalls.

Beyond assessing police structure, stakeholders placed a number of priorities on the Closing the Gap review, one of which was to '[s]afeguard the resilience of local (BCU/ Neighbourhood) services' (O'Connor, 2005 , p. 21). In other words, while Level 2 issues are undoubtedly important, any recommendations for restructuring must take into account the ramifications for addressing Level 1 criminality.

Protective services, the focus of the HMIC review, have been identified under the following seven broad headings:

- major crime (homicide);

- serious, organised and cross-border crime;

- counter-terrorism and extremism;

- civil contingencies;

- critical incidents;

- public order; and

- strategic roads policing.

The HMIC review considered individual forces' capability and capacity to provide for protective services and these were assessed against standards on intelligence, prevention and enforcement/resolution. HMIC found that very few of those forces assessed met the required standard and concluded that forces with over 4,000 police officers (or 6,000 staff in total) 'tended to meet the standard across the seven protective services measured' (O'Connor, 2005, p. 7). The review acknowledged the success of the current policing structure in reducing levels of volume crime, in contrast to the continued rise in many indicators associated with more serious crime and the protective services.

The review concluded, therefore, that a restructuring of the police service would provide increased resilience to support protective services and, at the same time, offer resilience in other areas, such as finance, where the review highlighted 'cost pressures' in the provision of (for example) forensic science and DNA analysis.

The recommendations of the review have received much attention, with some 
commentators claiming it represented 'the biggest shake-up of police in thirty years' (BBC, 2005). While much of the discussion around force mergers has focused on normative positions either for or against the HMIC review, precious little has been devoted to exploring empirically the impact amalgamation may bring.

To our knowledge Harrad (2006) represents the only independent, quantitative treatment of the implications of force mergers. She considered the economic argument for amalgamation and, while not arguing against it, concluded that without increased capacity "the case for amalgamation would at present need to be made on grounds other than cost and promises of better performance in those areas measured' (Harrad, p. 26).

In May 2006 John Reid was appointed Home Secretary and in little more than a month it was announced that he would not be pursuing compulsory force mergers as indicated by his predecessor. The critical issues appear to relate to cost, both of implementing mergers and to local authorities within merged forces. Future plans to fill the protective services gap have focused on assessing the strengths and weaknesses of a range of different operational configurations (such as inter-force operations, the lead force model and shared services).

The original intention of the analysis set out below was to compare and contrast volume crime performance of different forces so that mergers could be implemented to minimise the impact at Level 1 (ie by capturing and therefore not diluting good practice). Nevertheless, now that the police reform agenda has shifted to considering the benefits of different methods of working, we feel that comparing volume crime performance of different forces will go some way to informing the debate.

\section{DATA ANALYSIS}

Two main sources of data were used for this analysis. The first was the numbers of recorded criminal incidents and detections for six key offences in each BCU in England and Wales during 2004/05 (see Nicholas, Povey, Walker, \& Kershaw, 2005 for a description). Three offences - violence, sexual offences and robbery - were aggregated to produce a proxy for serious offending. Similarly, three property crimes - domestic burglary, theft of motor vehicle and theft from motor vehicle - were aggregated to derive a proxy for volume offences. The same procedure was used to yield detections for serious and volume offences. It should be noted that some crime categories (eg murder, drugs) will be excluded from this count, but the proxies contain the major offence types in both serious and volume crime. This should ensure that forces are compared appropriately.

The second source of information came from Home Office National Forensic Performance Monitors and Trackers. These measurements cover, for every police force in England and Wales, attendance, recovery and processing of both DNA and fingerprints for residential burglaries and theft of motor vehicles using a 'Forensic Impact' measurement method (Williams, 2004). It also includes the contribution made by forensic science to detecting residential burglaries and theft of motor vehicles. Each performance measure is graded red, amber or green depending on the performance of each force for that measure with respect to all other forces. An overall force grading is then produced based on an unweighted assessment of 14 contributing gradings. This is known as the forensic impact grading.

Scientific support managers in each police force submit to the Home Office a range of monitoring information on forensic science activity. Included in this are the numbers of crimes detected through 
forensic means. Incidents where forensic information contributed to the detection of an offender are labelled primary detections. Any further detections arising from a primary detection (offences taken into consideration, say) are labelled secondary detections.

In line with the Closing the Gap report, we partitioned forces into 'small' (less than or equal to 4,000 officers) and 'large' (greater than 4,000 officers). We also excluded the two London police forces on the following grounds: (a) the Metropolitan Police Service as it represents an extreme outlier with an officer strength of over 30,000 police officers (as at January 2005); and (b) the City of London Police because the residential population they serve is very small, about 7,000 (as at January 2005) and consequently the magnitude of volume crime dealt with is inconsequential. Excluding the London forces left a sample size of 5 forces considered large and 36 forces considered small.

We begin by comparing the detection rates for volume and serious crimes in BCUs. BCUs were partitioned into two groups according to whether they are located in forces which are considered small $(N=167)$ or large $(N=53)$ as defined earlier. In order to examine the difference between BCUs in small and large forces, we observed the distributions directly by estimating their density using a kernel density function. Essentially this is equivalent to a histogram for a continuous variable. The results are shown in Figure 1.

Figure 1 shows that the respective detection rates for volume and serious crime are basically the same for both groups, although BCUs in small forces appear to be located just to the right for both crime types, indicating slightly higher detection rates. The distributions for the small force BCUs share very similar 'spreads' with large force BCUs, although small force BCUs have a longer upper tail for both crime types, augmenting somewhat higher detection rates than BCUs in large forces. Thus, it appears BCUs in both small and large forces perform identically and where they do not it is BCUs from small forces which perform better than other BCUs (regardless of force size).

Our attention turns to whether the method of achieving detections varies between small and large forces. This is a challenging prospect as there are a multitude of factors at play that determine whether a given crime becomes detected:
Figure 1

Estimated distribution of detection rate of serious and volume crime of BCUs by force size

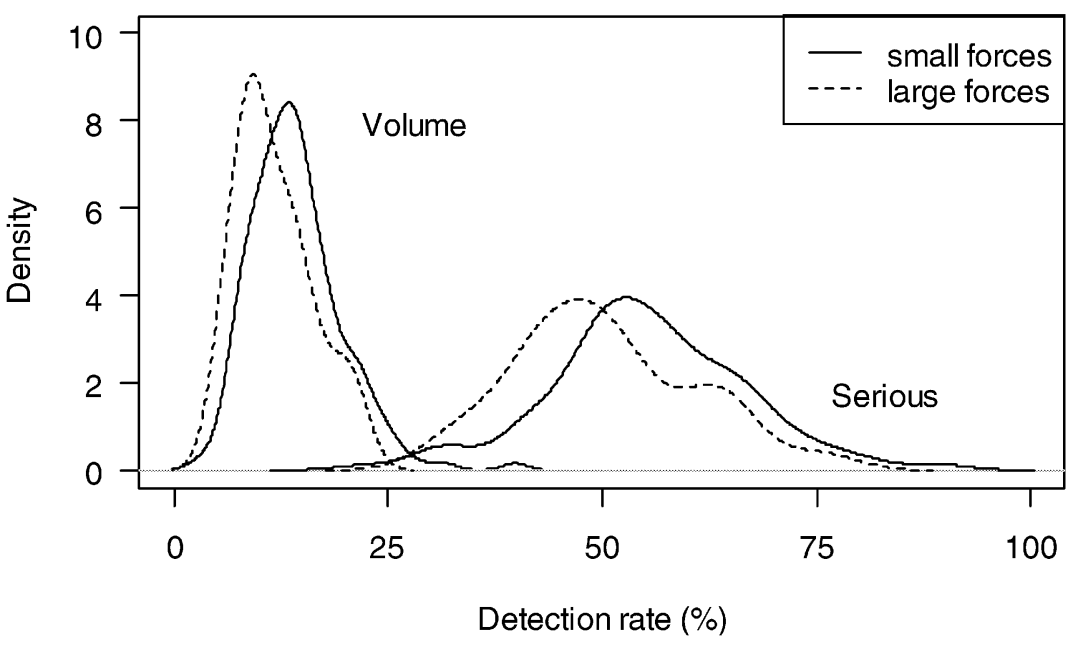


the discriminating modus operandi of the offender, the quality of recording, the extent of investigations, crime scene examiner presence and competence, interviewing strategy, levels of intelligence, and so on. One area on which there is reliable information is extent and outcome of forensic activity.

The only information to which we had access was aggregated at the force level. As there are only five police forces in the large category, density estimates on a sample size of five would be pointless. Instead we have simply displayed the distributions of proportion of primary detections due to forensic data type and police force size. Figure 2 shows the distributions using strip charts, a one dimensional equivalent of a scatterplot; each force is represented by an individual symbol.

Figure 2 shows two features worth noting. First, large forces, relative to small forces, do not vary much in their proportion of volume crime detected primarily through forensic means. Small forces are much more variable, ranging from 0.5 to 3.3 per cent for DNA-led detections compared with a range of 1 to 1.2 per cent for large forces. The pattern is repeated for fingerprint detections (1.1 to 2.7 per cent compared with 1 to 7.1 per cent). Second, the majority of small forces have a greater proportion of primary detections from forensic means than do large forces. Small forces are either as good as or better than large forces at detecting volume crime with forensics.

A further feature of the data not apparent from Figure 2 is that generally forces with high primary detection rates through fingerprints are the smallest forces. The correlations between force size and primary detections through fingerprint is $-0.49(p<$ $0.002)$ for all 41 forces used in the sample and $-0.36(p<0.033)$ for the 36 small forces. The corresponding correlation coefficients for DNA primary detections were non-significant.

How can the features of Figure 2 be interpreted? If it is known that detection

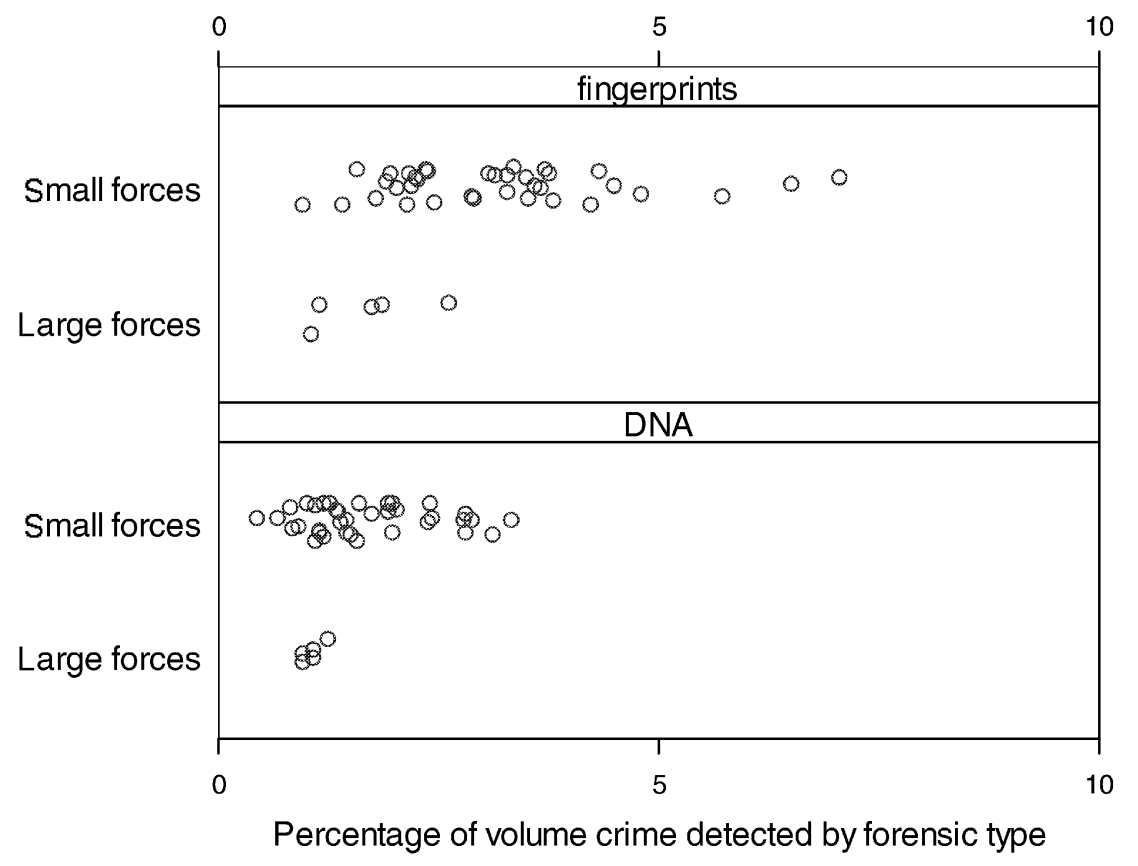

Figure 2

Distributions of primary volume detections by forensic type for different force types. (The actual values are jittered vertically to distinguish individual values and to minimise over-plotting of adjacent symbols.)

Percentage of volume crime detected by forensic type 
rates of serious and volume crime at the BCU level are largely independent of force size (analyses at the force level yield the same pattern) but at the force level there is a difference in the nature of volume detections, what could explain a higher apparent utilisation of forensic science among small forces? One hypothesis is that small forces do not possess the depth of investigator experience that large forces do. Perhaps large forces with higher numbers of cases are better placed to systematise procedures which have not yet transferred to small forces, or even that individual officers are exposed to a wider array of criminal behaviour on which they 'cut their teeth'. This could compel officers in small forces to rely on forensic solutions for detections to a greater degree than their counterparts in large forces.

An alternative explanation is that Scientific Support Units (SSUs) in small forces tend to collect more useful forensic material from crime scenes because they are managed in a different way, or the demand profile is different enough that allows them to do so.

It is inconceivable to test the former hypothesis (differential investigative expertise) using aggregate data. There are simply too many variables that will be inadequately captured by performance data that are easily available. In the not too distant future this may possible with the realisation of the Professionalising Investigation Process (Home Office, 2001). Instead, we focus on the second hypothesis regarding the variation of SSU performance.

The possible factors that allow small forces to collect more or different forensic material might be:

1. Superior scene attendance. Small forces may have greater resources at their disposal in certain situations. All things being equal, forces should have similar ratios for crime scenes to Crime Scene Examiners
(CSEs). This is likely to break down at the extremes, for either very small forces (there must be a minimum staffing threshold above which SSUs must maintain) or for large forces (when crime rates outstrip CSE recruitment, training and development). Substantially different ratios may result in some forces' attending a greater proportion of scenes; having more time to spend examining each scene; collecting more material/ scenes; or some combination of these.

2. Better evidence processing. The only area of forensic evidence that is conducted within forces and is common enough to yield a difference between detections is fingerprint matching. Thus, we are interested in the number of fingerprint experts each force possesses, their workload and their respective matching rates.

3. Some combination of the above.

The following analysis is carried out at the force level, as some forces do not have CSEs dedicated to BCUs (and, for reasons stated above, the Metropolitan Police Service and the City of London Police have been excluded from this analysis). In order to determine whether small forces enjoy per capita greater resources per scene, we calculated for each force the average number of crime scenes a CSE will attend annually. This was computed by summing the number of domestic burglaries attended, the number of theft of motor vehicle incidents attended and all serious crimes recorded for each force, and then divided by the number of CSE staff. We only counted attended volume criminal incidents as there is a fair degree of variation in attendance proportions. We assume that all serious criminal incidents are subject to some forensic response due to their rareness and nature. Note we have omitted scenes of theft from motor vehicle incidents in our calculations only because these are not included in the 


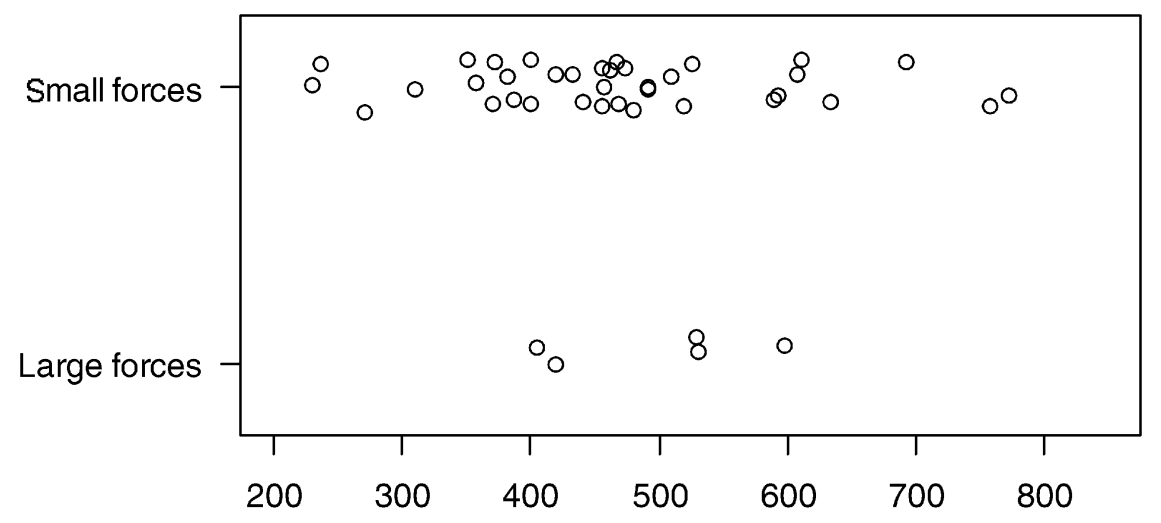

Number of crime scenes per examiner annually
Figure 3

Strip chart of scene to examiner ratio for large and small police forces. (The actual values are jittered vertically to distinguish individual values and to minimise over-plotting of adjacent symbols.)
Home Office forensic impact measurements available to us.

The mean number of scenes attended annually for small forces was 469.7 scene (per examiner, SD 128.9), compared with an average of 497.3 scenes per examiner for large forces (SD 82.3). In practical terms, if this mean difference was distributed uniformly throughout the year, CSEs in large forces would, on average, attend an extra crime scene every ten calendar days compared with their small force counterparts. Unsurprisingly then, a non-parametric hypothesis test failed to reject the null hypothesis of equivalent central tendency $(p=0.38)$. Figure 3 shows the two distributions using strip charts.

Figure 3 has a number of notable features. Within the two classes of police forces there is evidence of a large degree of variation, with CSEs in some forces potentially responding to almost double (large forces) or almost treble (small forces) the number of crime scenes as their counterparts in other forces. For instance, CSEs in small forces could potentially respond to between 250 crimes to nearly 800 annually.

There is little evidence that small forces enjoy greater per capita resources than large forces. While it is difficult to be prescriptive with a sample size of five, the distribution of the large forces' scene to examiner ratio is not dramatically different from that of the small forces.

The second factor feasibly influencing greater forensic utility among small forces is that of superior evidence processing. For this we rely on fingerprint expert performance as this function is housed intra-force. As all experts have identical training, differential performance of fingerprint bureaux indicates something about the organisation. Forces generally possess fingerprint experts in direct proportion to their officer strength (correlation of 0.88 ). Workload for fingerprint experts is measured by the number of cases (crimes) from which fingerprints are recovered and submitted to bureaux. If small forces are gathering information at more scenes, then we would expect the case to expert ratio to be significantly higher than for large forces. This ratio was computed for each force and the distribution is displayed in Figure 4.

The distributions shown in Figure 4 show a great deal of variation within forces of a given size. There is a three- and twofold difference between the highest and lowest ratios for small and large forces respectively. Importantly, though, there is no indication that fingerprint experts in small forces enjoy a lighter workload than 
Figure 4

Strip chart of case to fingerprint expert ratio for large and small police forces. (The actual values are jittered vertically to distinguish individual values and to minimise over-plotting of adjacent symbols.)

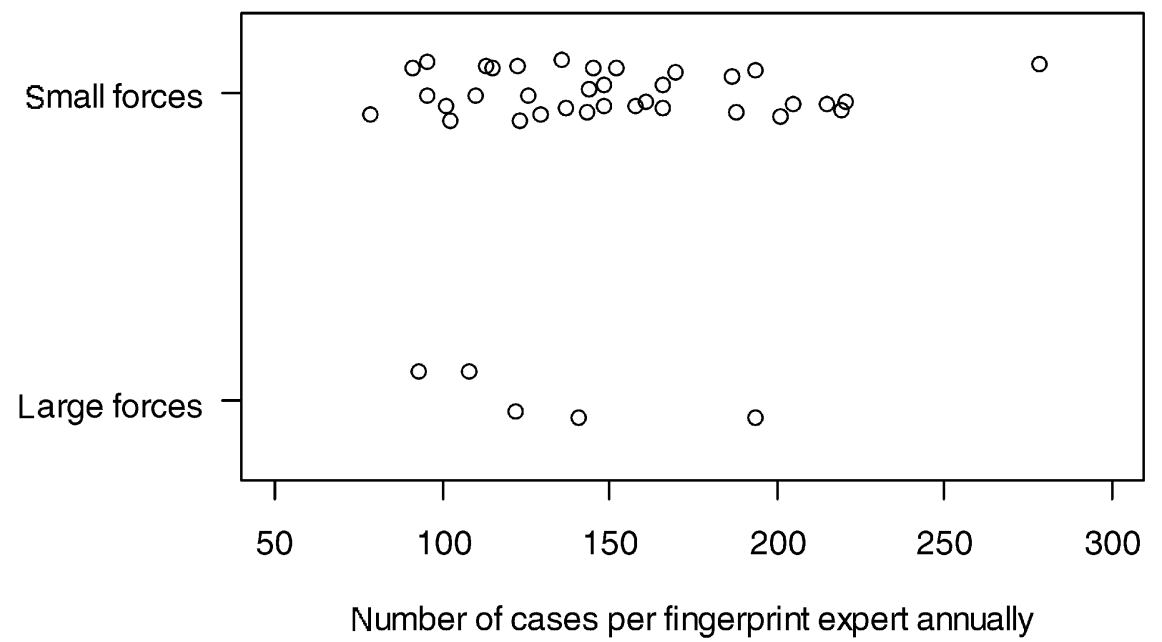

experts in large forces. If anything, experts in small forces appear to have a heavier volume crime case workload.

The next area of performance examined is the rate at which individuals are identified from crime scene fingerprint lifts. Here, we computed the number of identifications from fingerprints divided by the number of experts for each force. Figure 5 contains the results.

The features of Figure 5 worth noting are that small forces have a greater range than large forces and that this range is largely in a positive direction, ie towards identifying offenders for a greater proportion of criminal incidents.
To recap, small forces are similar to large forces with respect to the detection of volume and serious crime, crime scene examiner workload and fingerprint expert workload, but different in terms of method of volume detection and fingerprint expert performance.

\section{DISCUSSION}

Whilst a 'critical mass' of 4,000 police officers has been proposed by the HMIC review to provide adequately for protective services, it is apparent from this analysis that performance at detecting Level 1 criminality differs considerably within the existing
Figure 5

Identifications per fingerprint expert annually. (The actual values are jittered vertically to distinguish individual values and to minimise over-plotting of adjacent symbols.)

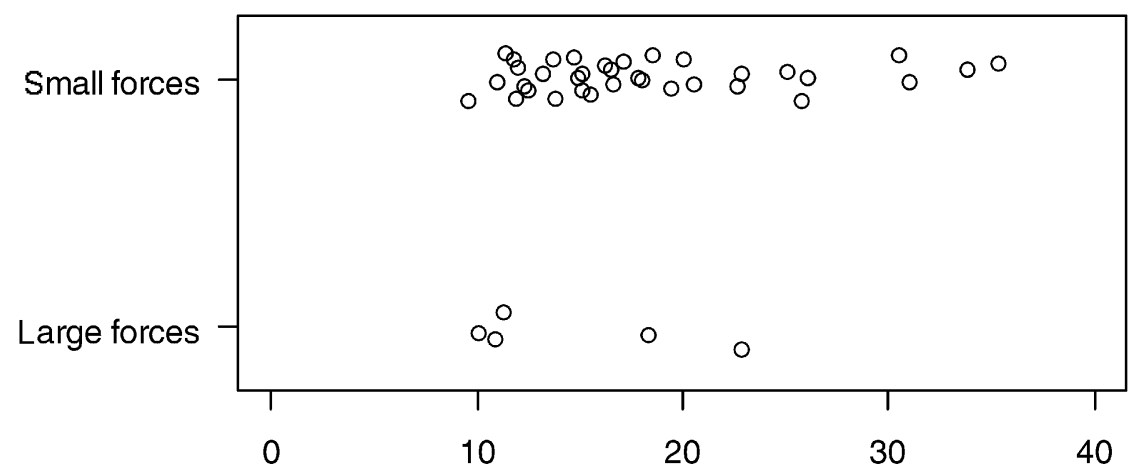

Number of identifications per fingerprint expert annually 
policing structure. For residential burglary and theft of motor vehicle offences, the Home Office data show that a significant percentage of detections for these crimes are brought about through DNA or fingerprints (ranging between 35 per cent and 7 per cent of total detections depending on force size).

In order to address the shortfall in performance amongst forces with more than 4,000 police officers, it is necessary to understand what small forces do that enables them to outperform their large neighbours. A clue to this may lie in the above analysis. The correlations observed may well be influenced by the opportunity in small forces to manage the forensic process positively and to focus on scenes most likely to provide forensic evidence able to detect the crime. Williams (2004) concluded that CSE performance was partially conditioned by the management of CSEs within the approach to volume crime investigation. Williams also stated that in forces where scientific staff were seen as 'expert collaborators', managers were able to exercise the greatest control over the CSE resource. Although Williams's research did not sample enough forces to comment on CSE deployment as a function of force size, his findings would be in keeping with the suggestion that the profile of forensic science in a force dictates the amount of CSE resource and its deployment.

The difference in the magnitude of correlation between DNA and fingerprint detections with force size may be further evidence of 'process management'. From the above analysis, the correlation between fingerprint primary detections and force size was deemed significant (-0.49), whereas the equivalent for DNA primary detections was not $(-0.11)$. This difference may well be attributable to the different processing methods for DNA and fingerprint evidence after the evidence has been collected at the crime scene. Fingerprint evidence is processed (and any identifications made) in-house by fingerprint staff (in some cases a neighbouring force). As such, there is more opportunity for managers to influence the workflow compared with DNA processing which is performed by one of a small number of service providers (independent of the police service) throughout the UK. Doubtless, in a small force, there is more opportunity to intervene in the fingerprint processing for individual crimes and to manage the process proactively.

It is unlikely that there is anything inherent in a small force that prevents its good practice being transferred to a large force but in implementing the HMIC review, and in considering different collaboration options for filling the protective services gap, the Home Office will need to pay careful consideration to the differences in forensic performance of different forces. Not to do so may have a considerable impact on the resiliency of domestic protective service capability.

\section{Acknowledgements}

The authors acknowledge the assistance of Mrs Trudy Loe (Northamptonshire Police) with the analysis of the data presented in this paper. One of us (JWB) gratefully acknowledges the support of the chief officers of Northamptonshire Police.

\section{References}

BBC. (2005). Clarke Attacked on Police Reform. Retrieved March 24, 2006 from http:// news.bbc.co.uk/1/hi/uk_politics/ 4541012.stm. 
Harrad, L. (2006). Are Larger Police Forces Better than Smaller Police Forces? Police Professional, 44, 24-26.

Home Office. (2001). Policing a New Century: A Blueprint for Reform (White Paper, Cm 5326). London: Home Office.

Nicholas, S., Povey, D., Walker, A., \& Kershaw, C. (2005). Crime in England and Wales 2004/2005 (Home Office Statistical Bulletin 11/05). London: Home Office. O'Connor, D. (2005). Closing the Gap: A Review of the 'Fitness For Purpose' of the Current Structure of Policing in England and
Wales. London: Her Majesty's Inspectorate of Constabulary.

Stephenson, P. (2004). What Would a Level 2 Model of Policing Look Like and What Would Be the Specifications of the Services that it Would Offer? (Report to ACPO Police Reform Steering Group (Restricted Access)). London: ACPO.

Williams, R. (2004). The Management of Crime Scene Examination in Relation to the Investigation of Burglary and Vehicle Crime (Home Office Online Report 24/10). London: Home Office. 